\title{
Allocation For Wi-Fi Devices At Campus of Udayana University in Bukit Jimbaran Using Atoll Applications
}

\author{
Sudiarta Pande Ketut ${ }^{1}$, Pramaita Nyoman ${ }^{2}$ \\ Electrical and Computer Engineering \\ Engineering Faculty, Udayana University \\ Bali, Indonesia \\ sudiarta@unud.ac.id \\ Electrical and Computer Engineering \\ Engineering Faculty, Udayana University \\ Bali, Indonesia \\ n_pramaita@yahoo.com
}

\begin{abstract}
Access to intranet and internet networks in the campus area requires a number of Wi-Fi devices to cover the coverage area of Udayana University. The Wi-Fi service is expected to be used for VoIP applications in the context of wireless communications. The IEEE $802.11 \mathrm{~g}$ standard specifies an outdoor service range of $140 \mathrm{~m}$ and an indoor service range of $38 \mathrm{~m}$. From research conducted in the engineering faculty area, the quality of VoIP service uses Wi-Fi with range of $25 \mathrm{~m}$. In this research, the design of Udayana University campus Wi-Fi needs using Atoll application with IEEE802.11g standard at 140 $\mathrm{m}, 38 \mathrm{~m}$ and $25 \mathrm{~m}$ ranges. The results obtained to cover Udayana University campus area require Wi-Fis: 7 units for range $140 \mathrm{~m}$, 98 units for range of $38 \mathrm{~m}$ and 225 units for range of $25 \mathrm{~m}$
\end{abstract}

Index Terms-WIFI, 802.11g, Wireless.

\section{INTRODUCTION}

Udayana University has a very wide area where the faculties are distributed in different location. Since a faculty location to another is seperated in a distance, digital information services can be obtained efficiently via intranet or internet network. Therefore, it is required Wifi services that are able to cover all location in the campus area. In addition to the coverage, Wifi services are expected to have a quality service that is able to pass VOIP information, and hence the network at Udayana University can be developed into a wireless internal VoIP network.This is in accordance with Sudiarta research results, Utilization of hotspot network for Telephone Communication using Smartphone and Free Software as campus internal communication [1], since the use of a wireless internal VoIP network can save phone expenses on campus.

IEEE $802.11 \mathrm{~g}$ is a Wi-Fi standard that can reach a distance of $140 \mathrm{~m}$ for outdoor conditions and $38 \mathrm{~m}$ for indoor conditions [2]. In this study have been tested two units of Wi-
Fi devices with IEEE802.11g standard in the area of Engineering Faculty with quality that can be used in VOIP service. From the research conducted, it was obtained average distance range of $25 \mathrm{~m}$. Although it is done outdoors but the range is relatively close to indoor conditions due to some reasons including quality expected to skip VoIP service, placement of Wi-Fi close to the building wall using omnidirectional antenna and conditions of measurements around the building where there are many barriers between them.

This research focus is to design Wi-Fi device needs for Udayana University Campus using Atoll application [3], IEEE $802.11 \mathrm{~g}$ standard Wi-Fi devices on the range of $140 \mathrm{~m}$, $38 \mathrm{~m}$ and $25 \mathrm{~m}$. Wi-Fi devices are assumed to be at heights of $5 \mathrm{~m}$ with standard model propagation. The antenna used is omnidirectional $2.5 \mathrm{dBi}$. 


\section{METHOD}

Investigation method for Wi-fi devices allocation at Kampus Bukit Jimbaran Udayana University is shown in the flowchart below, and the tools used for the investigation are GPS, 2 units of Wi-fis supporting standard IEEE802.11g, Atoll application, VoIp server and mobile phone for VoIp testing .

The IEEE802.11 has released multiple sets of standards for various operating frequencies, and ranges of specifications. The first release was IEEE802.11 as an original standard defined in 1997 and clarified in 1999. [4] Some of these old standards are now obsolete, and some are still active. One would be interested in investigating in details the available standards to determine a suitable standard for the intended application of the WLAN network.

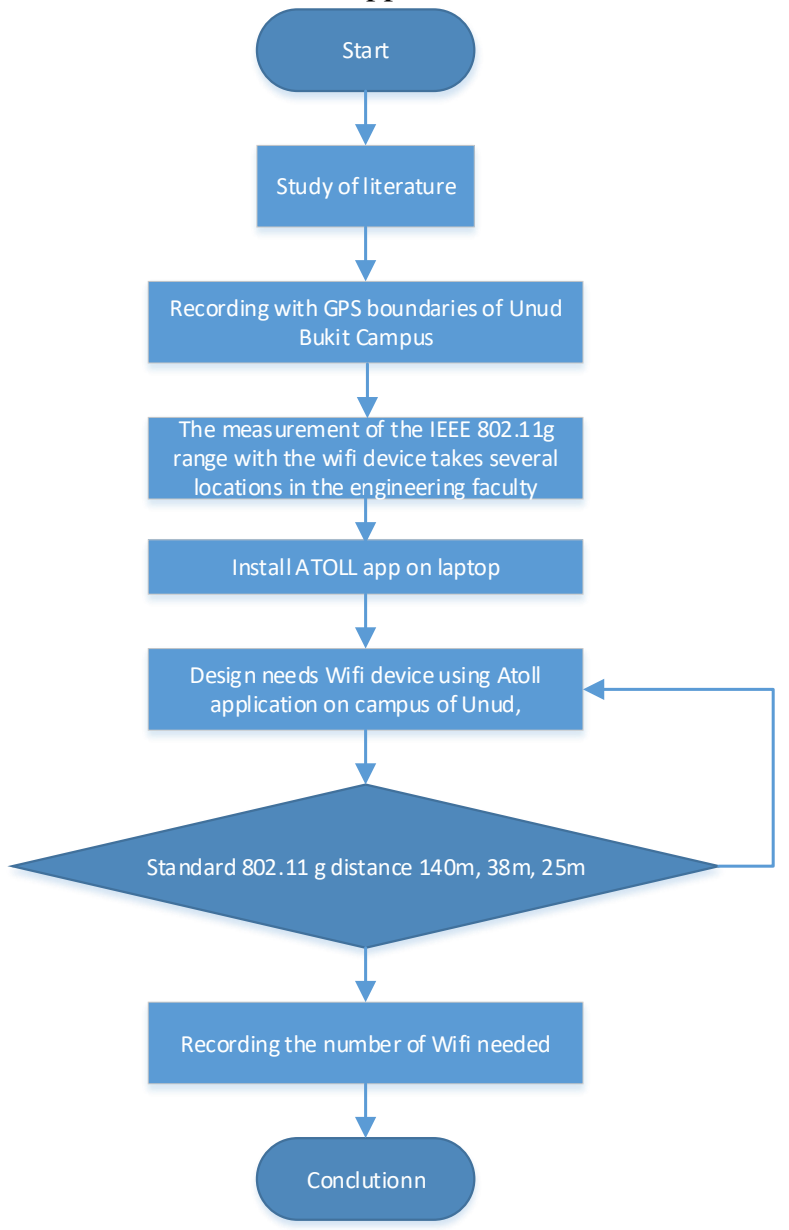

\section{IEEE $802.11 \mathrm{~g}$}

The standard $802.11 \mathrm{~g}$ was ratified in 2003 as an IEEE standard for Wi-Fi wireless networking and it supports maximum network bandwidth of $54 \mathrm{Mbps}$ compared to 11 Mbps for $802.11 \mathrm{~b}$. This standard operates at $2.4 \mathrm{GHz}$ frequency and bandwidth of $20 \mathrm{MHz}$. This standard uses the OFDM or DSSS modulation schemes. This standard employs the SISO antenna technologies, and its indoor / outdoor ranges are from $38 \mathrm{~m}$ to $140 \mathrm{~m}$ respectively.

\section{RESULT}

A. Scenario for measuring IEEE $802.11 \mathrm{~g}$ coverage with VoIP quality

Test conducted by research scenario is presented in figure 1.

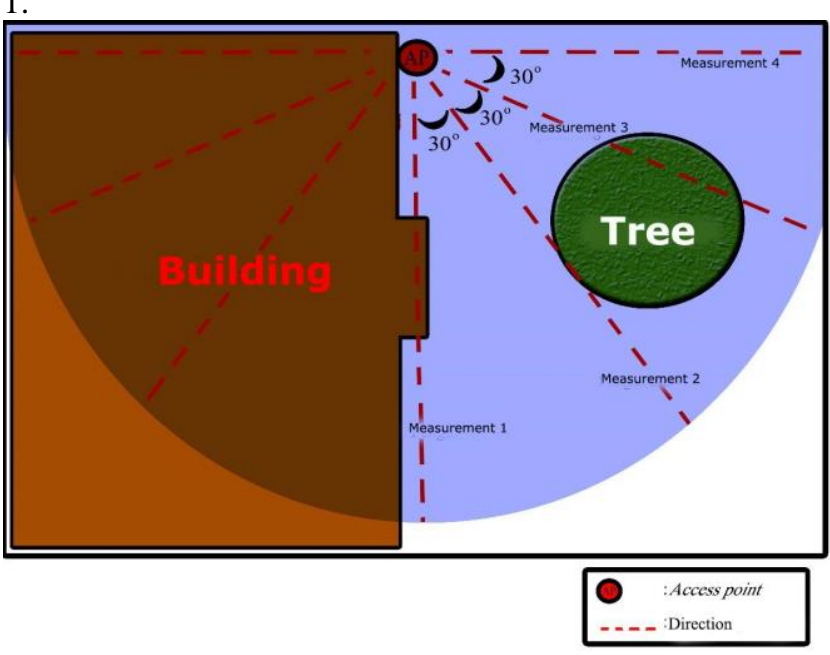

Fig. 1. Testing Scenario

The average service coverage of IEEE802.11g for VoIP conditions is still well received in the area of Faculty of Engineering at Udayana University, that is in the range of 25 meters for outdoor conditions. This is due to several factors namely: 1. Placement Access Points are almost attached to the wall of the building, and type of antennas used is omnidirectional so that the reflection will give effect closed to the indoor approach conditions. 2 The number of building blocks and trees are overwhelming, and 3. Measurements on VoIP quality are still feasible.

\section{B. Atoll Installation}

Installation of Atoll applications was performed on laptops with specifications of Intel Core I7, $1.5 \mathrm{GHz}$ CPU, 4 GB Memories, and 10-version of 32 bits-Windows operating system.

Figure 2 shows the Atoll Application using WGS84 50S Coordinate with clutter, altitude and vector of Bali map.

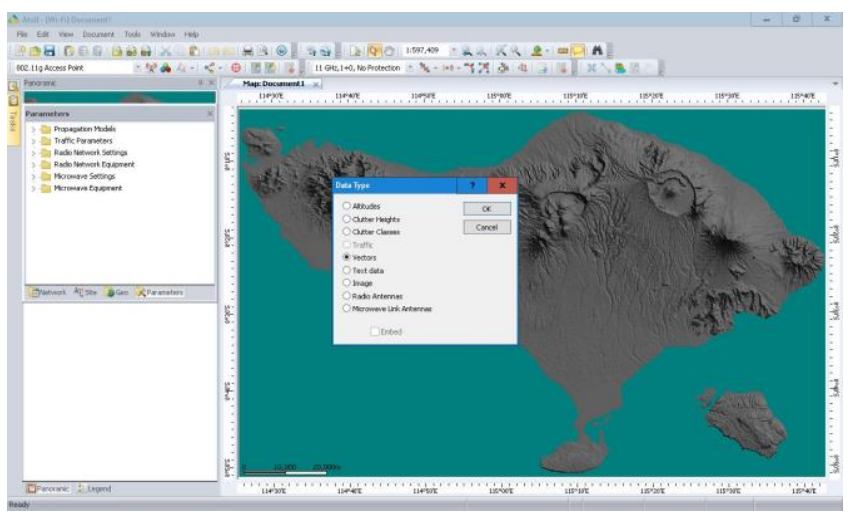

Figure 2. Atoll Aplications with Bali map 


\section{The Coverage of Campus of Unud Bukit}

From the measurement of campus area of Udayana University (Unud) using GPS, then using the Google Earth application, the coverage of Campus of Unud can be delineated as shown in Figure 3. Campus locations such as valleys that no buildings are not included in the planning of Wi-Fi campus area.

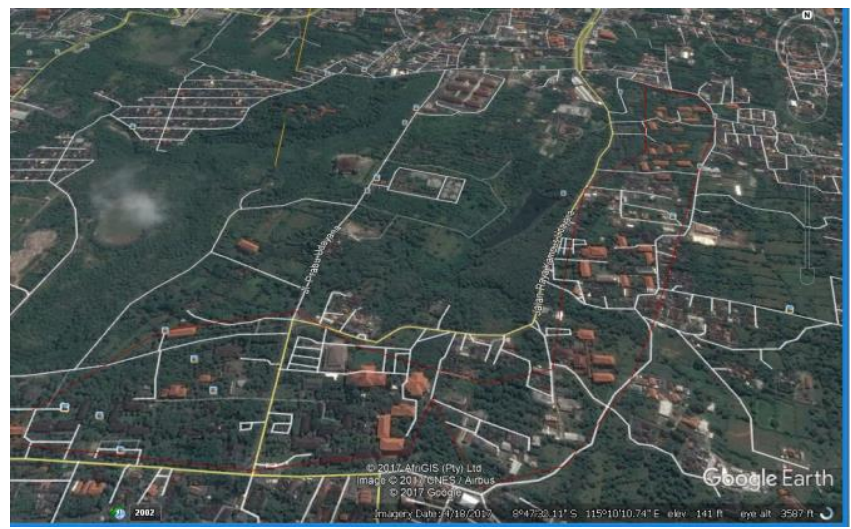

Figure 3. The Coverage of Campus of Unud Bukit

\section{Design using Atoll at $140 \mathrm{~m}, 38 \mathrm{~m}$ and $25 \mathrm{~m}$ ranges}

In accordance with the IEEE802.11g outdoor standard, the design needs of Wi-Fi devices in the area of Unud Campus was set in the range of $140 \mathrm{~m}$. The design result is shown in Figure 4, where the number of access points required is 7 units with the downlink signal distribution shown on the color coverage, the smaller the signal level obtained by the outer circle.

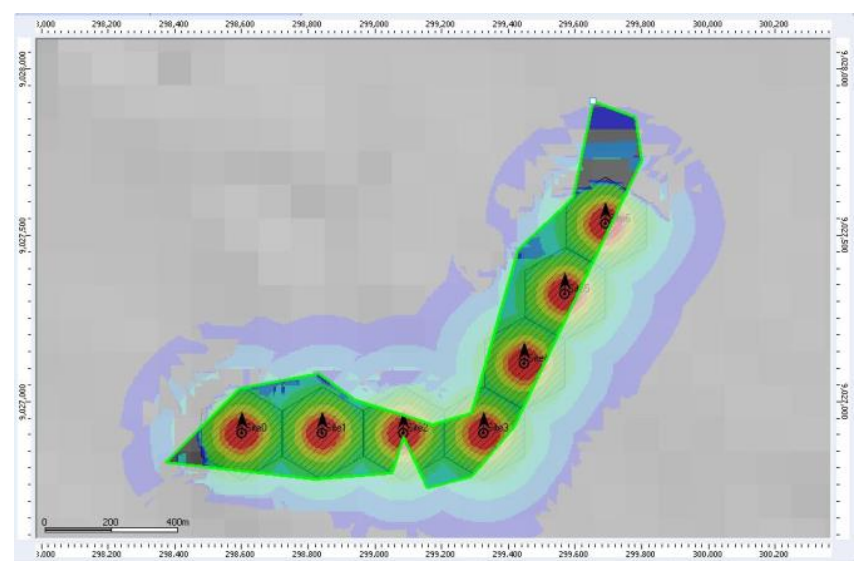

Figure 4. The number of Wi-Fi devices IEEE802.11g in the range of $140 \mathrm{~m}$

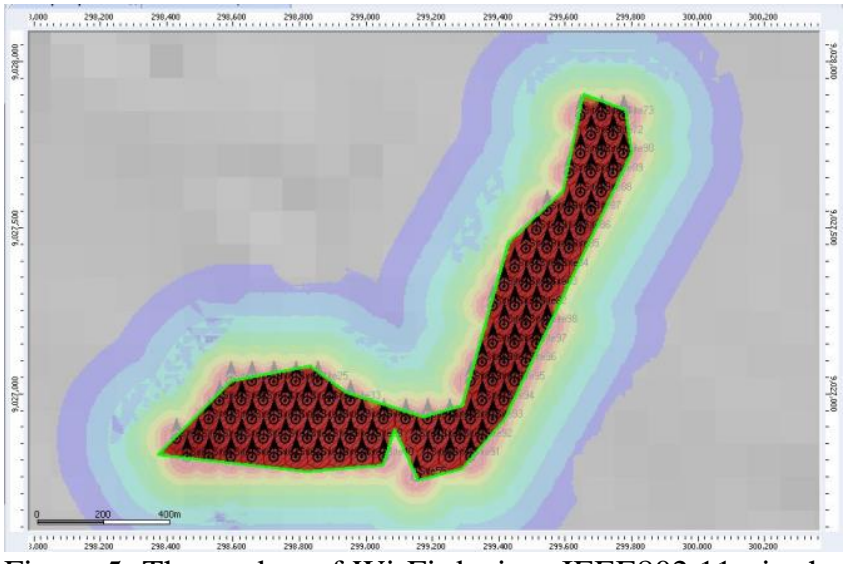

Figure 5. Thenumber of Wi-Fi devices IEEE802.11g in the range of $38 \mathrm{~m}$

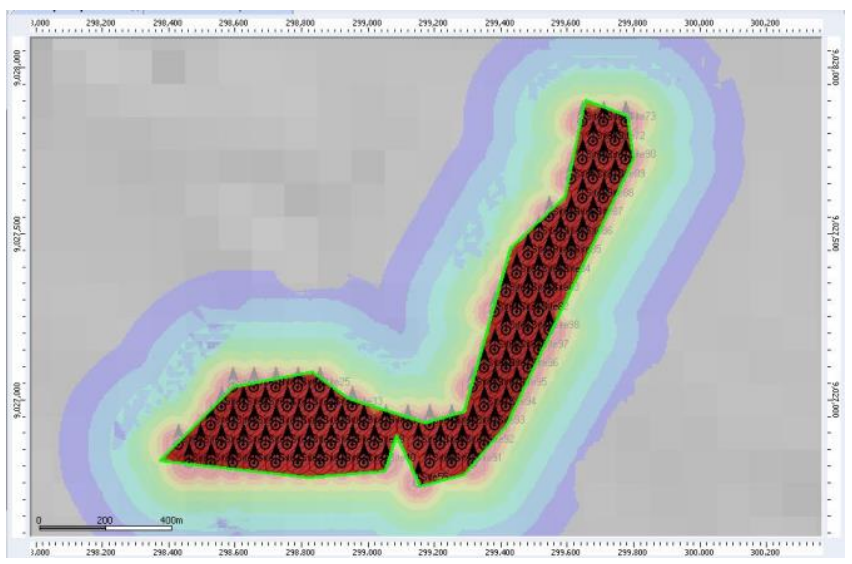

Figure 5. The number of Wi-Fi devices IEEE802.11g in the range of $38 \mathrm{~m}$

Figure 5 shows the number of $\mathrm{Wi}$-Fi devices required when referring to the IEEE802.11g indoor standard with a range of $38 \mathrm{~m}$. By using propagation model of Standard Propagation Medel and AP height 5 meters. As is also used at a distance of $140 \mathrm{~m}$ then the number of Wi-Fi devices required is 98 units

While in Figure 6 disclose the amount of Wi-Fi required if the range is $25 \mathrm{~m}$. From the design required $225 \mathrm{Wi}-\mathrm{Fi}$ devices to cover the campus unud

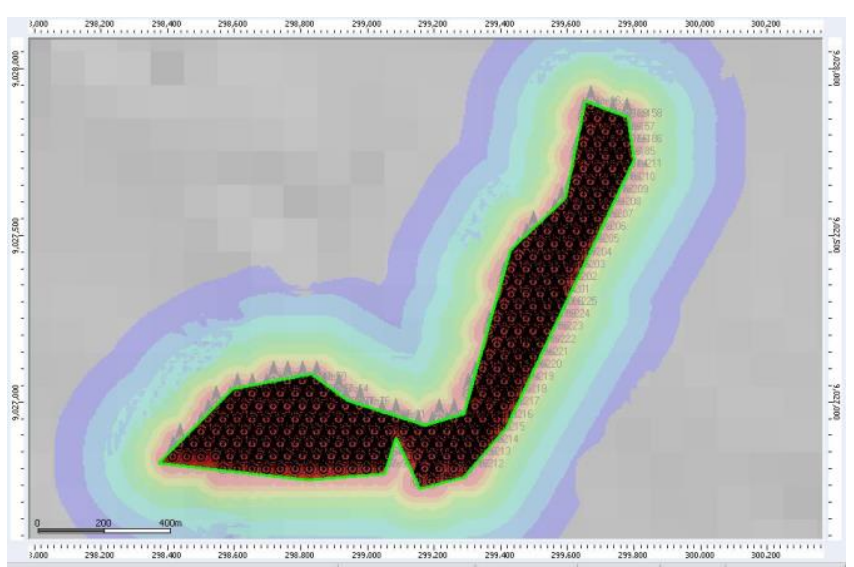


Figure 6. The number of Wi-Fi devices IEEE802.11g in the range of $25 \mathrm{~m}$

Table 1. The Wi-Fi requirement per standard used

\begin{tabular}{|r|r|l|r|}
\hline No & \multicolumn{1}{|c|}{$\begin{array}{c}\text { Range } \\
(\mathrm{m})\end{array}$} & \multicolumn{1}{|c|}{ Standard } & \multicolumn{1}{|c|}{$\begin{array}{l}\text { Wi-Fi } \\
\text { (Unit) }\end{array}$} \\
\hline 1 & 140 & IEEE802.11g Outdoor & 7 \\
\hline 2 & 38 & IEEE802.11g Indoor & 98 \\
\hline 3 & 25 & with Voip quality & 225 \\
\hline
\end{tabular}

Table 1 shows the IEEE802.11g standard Wi-Fi requirements of each outdoor, indoor and VoIP quality used.

\section{DISSCUSION}

IEE802.11g gives 2 standards that are for indoor service $(38 \mathrm{~m})$ and outdoor $(140 \mathrm{~m})$. However, in this study the authors add another distance of $25 \mathrm{~m}$ in order to the $\mathrm{Wi}-\mathrm{Fi}$ design results can be used for VoIP service with good quality. The result of $25 \mathrm{~m}$ range is caused by the $\mathrm{Wi}-\mathrm{Fi}$ laying closed to wall with omnidirectional antenna and reflection from adjacent buildings so that it is closed to indoor condition. But this study results still consider any distribution of people evenly. So that later on the highway, the number of Wi-Fis can be reduced.

\section{CONCLUSIONS}

Based on the research conducted, the needs for the WiFi devices to cover the area of Unud Bukit Jimbaran campus are as follows:

1. In accordance with the IEEE 802.11g outdoor standard with a distance of $140 \mathrm{~m}$, it is required 7 units of Wi-Fi devices.

2. It is required 98 units of $\mathrm{Wi}-\mathrm{Fi}$ devices according to the IEEE $802.11 \mathrm{~g}$ indoor standard with a distance of 38 .

3. According to IEEE $802.11 \mathrm{~g}$ standard with VoIP quality with $25 \mathrm{~m}$ distance, it is required 225 units of $\mathrm{Wi}-\mathrm{Fi}$ devices.

From the research conducted, the following suggestions are as follows:

1. It is required further research to analyze Wi-Fi requirement, only in area of buildings in campus area Unud.

2. Further research is required in terms of relating traffic and Wi-Fi needs.

\section{REFERENCES}

[1] Pande Ketut Sudiarta, Implementation Of Hotspot Network for internal campus Communications Utilizing Smartphone and Free Software, Journal of Electrical, Electronic and Informatics, ISSN 2549-8304, Vol.1No.1 February 2017.P33-37

[2] Ramia Babicar Mohammed Abdelrahman, A Comparison Between IEEE802.11a,b,g,n and ac Standards, IOSR Journal of Computer Engineering (IOSR-ICE), e-ISSN:2278-0661,p-ISSN:2278-8727, Vol.17, Issue 5, Ver III (Sep-Oct.2015),PP26-29

[3] Atoll, http://www.forsk.com/atoll-overview, accessed Nopember 14, 2017
[4] IEEE 802.11, https://en.wikipedia.org/wiki/IEEE_802.11, accessed Nopember 14, 2017. 